\title{
Design and Analysis of Highly Efficient Led Power Supply with Pfc-LLC Topology
}

\author{
Xiu-Min WANG ${ }^{1, a}$, Chen SU ${ }^{1, b}$, Li-Ting JIANG $^{1, c}$, Ri-Hui XIONG ${ }^{1, d}$ and Jian- \\ Bing $X^{2, e}$
}

${ }^{1}$ China Jiliang University, College of Information Engineering, 310018 Hangzhou, China

${ }^{2}$ Shine Light Technology Co., Ltd, 311121 Hangzhou, China

Keywords: Resonance power supply, MATHCAD, Zero-voltage-switching, Power efficiency, PFC-LLC circuit.

\begin{abstract}
A half-bridge light emitting diode drive resonance power supply which consist of power factor correction rectifier and inductor-inductor-capacitor resonant topology circuit, the controller for each part is ST6562 and L6599 chip, respectively. This design and analysis has been presented. The MATHCAD is used for system design and to optimize resonant parameters to achieve improved power efficiency of light emitting diode drive resonance circuit. By using sinusoidal analysis we study the characteristics of voltage gain. We achieve zero-voltage-switching and zerocurrent-switching functions by SABER simulation. The experimental results show that the proposed method achieves high power efficiency $91.5 \%$ and smooth electromagnetic interference by comparing it with the other literatures.
\end{abstract}

\section{Introduction}

With the continuous development trend of low energy consumption and high power density in emitting diode (LED) drive resonance power supply, the traditional hard-switching technology has limitations when it comes to efficiency in terms of losses and electromagnetic interference. During switching time phase angles of the voltage and current should be kept as a certain gap to reduce conduction losses and noises [1]. Ideal resonant network parameters are the premise to guarantee reliable operation for soft-switching converter. This paper provides an in-depth analysis of halfbridge inductor-inductor-capacitor (LLC) resonant converter by soft-switching techniques. By using sinusoidal analysis and MATHCAD simulation, we optimize LLC resonant network parameters for improved system performance. Finally we use SABER software to simulate schematic diagrams of power factor correction (PFC) circuit and LLC resonant circuit by our optimized parameters. Another contribution of this paper is to design a drive power supply based on ST6562 chip as PFC controller and L6599 chip as high voltage resonant controller. The system performance is verified by simulation as well as test results.

Fig.1 shows the block diagram of PFC-LLC circuit. For high power LED drive supply, boost circuit can achieve PFC performance. LLC half-bridge resonant circuit can solve the problem of power losses [2]. In this paper, we adopt PFC control circuit based on ST6562 chip with voltagemode which can effectively reduce the total harmonic distortion. And it can adjustably control resonant frequency and reduce electromagnetic interference. The designed circuit adopts LD6599 chip as voltage-mode controller which can make voltage or current periodical zero-crossing when circuit resonance occurs. It makes power switches turn on and turn off in zero-voltage-switching (ZVS) and zero-current-switching (ZCS) conditions and improves the efficiency of power supply.

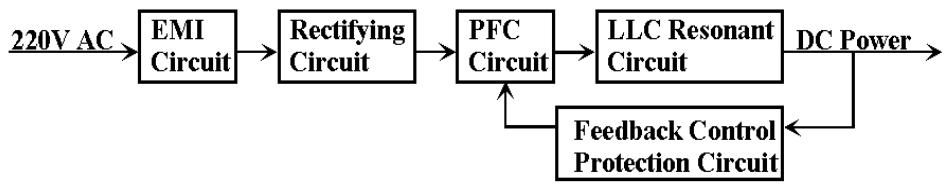

Fig. 1 Block diagram of PFC-LLC circuit 


\section{Analysis of LLC Half-bridge Resonance Converter}

Fig. 2 shows the topology of half-bridge LLC resonant circuit. Half-bridge resonant converter has been widely used because of simple structure, higher magnetic integration and lower switching loss performance. We use sinusoidal analysis to analyze the equivalent model of LLC resonant converter as shown in Figure 2 [3].

Figure 2 shows the equivalent model circuit which mainly includes primary power tubes $\mathrm{S} 1$ and $\mathrm{S} 2$, resonant capacitance $\mathrm{Cr}$, resonant inductor Ls, excitation inductance $\mathrm{Lm}$, rectifier diode D3, D4 and output filter capacitor $\mathrm{C}_{\mathbf{f}}$. LLC resonant conversion circuit has two resonant frequencies. Resonant inductance Ls and resonant capacitance $\mathrm{Cr}$ comprise first resonant frequency $f r_{1}$. The second resonant frequency $f_{2}$ is composed of $L m$, Ls, and $C r$. The working mode of pulse frequency modulation (PFM) control can be divided into three modes by the relationship of switching frequency $f_{s}$ and resonant frequency. Mode $1\left(f s>f r_{2}\right)$ : Circuit can realize power switch ZVS when it is working in inductive zone, but it is unable to realize the rectifier ZCS. Mode $2\left(f r_{1}<f s<f r_{2}\right)$ : Circuit can realize ZVS function of power switches and ZCS function of rectifier diodes when it is working in inductive zone. Mode $3\left(f s<f r_{1}\right)$ : Circuit is unable to realize ZVS and ZCS functions when it is working in capacitive zone. With respect to the vibration switching frequency $f_{s}$ in range of $f r_{1}$ to $f r_{2}$, we will take different time segment to specific analysis during one switch cycle. In order to achieve soft-switching performance, we analyze relationship of resonant parameters in different time segment which are interrelated from the ideal performance point. We use MATHCAD simulation software to simulate its voltage gain waveform and do concrete research according to simulation waveform of the three modes.

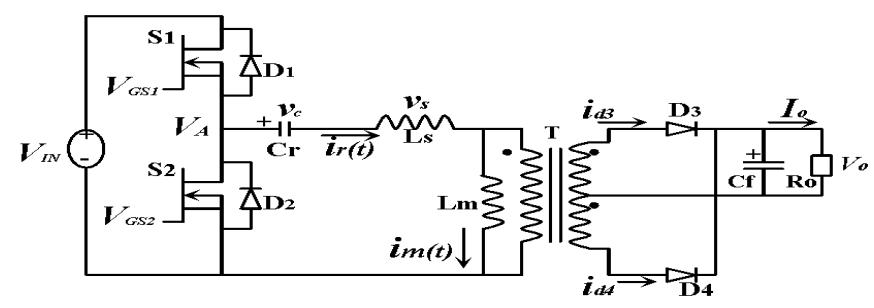

Fig. 2 Topology of half-bridge LLC resonant circuit

\section{Analysis of LLC Half-bridge Resonance}

Fig. 3 shows ideal waveform of LLC half-bridge resonant network. We can analyze the relationship of resonant parameters to achieve soft-switching performance.

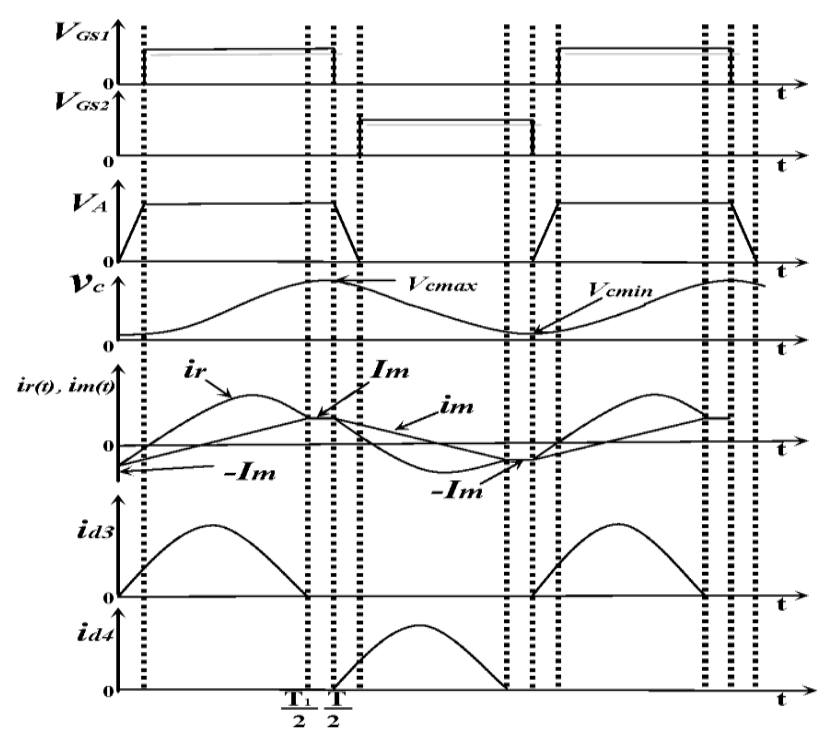

Fig. 3 Ideal waveform of LLC half-bridge resonant network 
On the interval $\left(0, T_{1} / 2\right)$, circuit works on the first resonant frequency $f r_{I}$ with only Ls and $\mathrm{Cr}$ in resonance. Voltage of $\mathrm{Cr}\left(v_{c}\right)$ will be clamped by output voltage when current $i_{m}$ increases linearly to $I_{m}$ at time $T_{1} / 2$. In order to realize the function of power switches ZVS, driving voltage $V_{G S I}$ of the power switch S1 discharges to zero when the junction capacitance of power switch S2 is charging.

$$
\begin{aligned}
i_{m}(t) & =\frac{n v_{o}}{L_{m}} t-I_{m} \\
i_{r}(t) & =I_{r} \sin \left(\omega_{s} t-\varphi\right)
\end{aligned}
$$

Where, $I_{m}$ is maximum excitation inductance current, $n$ is the turn ratio of transformer T and $V_{o}$ is output voltage. $\omega_{s}, \varphi$ respectively represent the angular frequency and initial phase of the $i_{r}, I_{r}$ is the maximum value of $i_{r}$.

Interval $\left(T_{1} / 2, T / 2\right)$ must be inserted a dead time when current of rectifier diodes reduces to zero. So excitation inductance current $i_{m}$ can reach maximum Im and the rectifier diodes achieve ZCS function. So on the interval $\left(T_{1} / 2, T / 2\right)[4]$ :

$$
\begin{aligned}
& i_{m}(t)=i_{r}(t)=I_{m} \\
& i_{m}(0)+i_{m}\left(T_{1} / 2\right)=0 \\
& I_{m}=\left(n V_{o} T_{1}\right) /\left(4 L_{m}\right) \\
& i_{m}(0)=i_{r}(0) \\
& I_{r} \sin \varphi=I_{m}
\end{aligned}
$$

On the interval $(0, T / 2)$, resonant capacitance $\mathrm{C}_{\mathrm{r}}$ is charging when output current is $I_{o}$. Average charging current $I o / n$ is the secondary side current of transformer T, so $v_{c}$ symmetrically charges from minimum $V_{c m i n}$ to maximum $V_{c m a x}$, so we find

$$
\begin{aligned}
I_{o} T & =2 n \int_{0}^{\frac{T}{2}}\left[i_{r}(t)-i_{m}(t)\right] d t \\
& =2 n \int_{0}^{\frac{T_{1}}{2}}\left[I_{r} \sin \left(\omega_{s} t-\varphi\right)-\frac{n v_{0}}{L_{m}} t+I_{m}\right] d t \\
& =2 n \int_{0}^{\frac{T_{1}}{2}} I_{r} \sin \left(\omega_{s} t-\varphi\right) d t \\
& =\frac{2 n T_{1}}{\pi} I_{r} \cos \varphi \\
I_{r} & =\sqrt{\left(\frac{\pi I_{o}}{2 T_{1} n}\right)^{2}+I_{m}^{2}}
\end{aligned}
$$

Because resonant energy will be stored in the circuit when resonant capacitance $\mathrm{Cr}$ is resonance occurring. Then the output power and $v_{c}$ will increase with the decrease of $C r$. So the following task is to get the approximate formulas analysis for peak voltage $V_{c m a x}$ of $\mathrm{Cr}$ capacitance. On the interval $(0, T / 2), v_{c}$ reaches maximum $V_{c m a x}$ at time $T / 2$.

$$
\begin{aligned}
& v_{c}\left(\frac{1}{2} T\right)-v_{c}(0)=\frac{1}{C_{r}} \int_{0}^{\frac{T}{2}} i_{r}(t) d t \\
= & \frac{1}{C_{r}}\left(\int_{0}^{\frac{T_{1}}{2}} I_{r} \sin \left(\omega_{s} t-\varphi\right) d t+\int_{\frac{T_{1}}{2}}^{\frac{T}{2}} I_{m} d t\right)
\end{aligned}
$$




$$
\begin{aligned}
& V_{i n}=v_{c}\left(\frac{1}{2} T\right)+v_{c}(0) \\
& v_{c}(0)=\frac{1}{2} V_{i n}-\frac{I_{o} T}{4 n C_{r}}-\frac{I_{m}}{4 C_{r}}\left(T-T_{1}\right) \\
& V_{c \max }=v_{c}\left(\frac{T}{2}\right)=\frac{1}{2} V_{i n}+\frac{I_{m}}{4 C_{r}}\left(T-T_{1}\right)+\frac{I_{o} T}{4 n C_{r}}
\end{aligned}
$$

The above formula (13) can be rewritten as follows

$$
\begin{aligned}
& V_{c \text { max }}=n V_{0}+\frac{I_{0} T}{4 n C_{r}} \\
& C_{r}=\frac{I_{0}}{4 n f_{s \text { min }}\left(V_{c \text { max }}-n V_{0}\right)}
\end{aligned}
$$

Where, $f_{\text {smin }}$ is the minimum switching frequency.

After determining $C r$, the resonant inductance $L s$ can be obtained from (16) according to the resonant frequency range.

$$
\begin{aligned}
& f_{r 1}=\frac{1}{T_{1}}=2 \pi \sqrt{L_{s} C_{r}} \\
& L_{s}=\frac{1}{4 \pi^{2} f_{r 1}^{2} C_{r}}
\end{aligned}
$$

Optimal excitation inductance $L m$ is derived. Designing $L m$ directly affects the realization of soft-switching performance. The conduction loss of power switches increase with the increase of excitation current $i_{m}$ when $L m$ is too small. If $L m$ is too large, then the current $i_{m}$ in the dead time will be too small. So it makes the junction capacitance of power switches have not enough time to discharge. Therefore it is difficult to achieve the soft-switching performance. So designing the optimized $L_{m}$ can make resonant circuit works in a good performance.

In addition to the power consumption of resonant inductance Ls, transformer $\mathrm{T}$ passes the input voltage $V_{\text {in }}$ almost all to secondary side [5], so we find

$$
v_{s}(0)=L_{s} \frac{d i_{r}(0)}{d t}=\omega_{s} L_{s} I_{r} \cos \varphi
$$

Where, $v_{s}(0)$ is the voltage of the resonant inductor $v_{s}$ at time 0 .

$$
\begin{gathered}
n V_{0}=V_{i n}-v_{c}(0)-v_{s}(0) \\
=V_{i n}-\frac{1}{2} V_{i n}+\frac{I_{o} T}{4 n C_{r}}+\frac{I_{m}}{4 C_{r}}\left(T-T_{1}\right)-\omega_{s} L_{s} I_{r} \cos \varphi \\
=\frac{1}{2} V_{i n}+\frac{I_{m}}{4 C_{r}}\left(T-T_{1}\right)+\frac{I_{0} T}{4 n C_{r}}-\omega_{s} L_{s} I_{r} \times \frac{I_{0} T \pi}{2 n T_{s} I_{r}} \\
=\frac{1}{2} V_{i n}+\frac{I_{m}}{4 C_{r}}\left(T-T_{1}\right)+\frac{I_{0} T}{4 n C_{r}}-\frac{1}{\sqrt{L_{s} C_{r}}} \cdot L_{s} \cdot \frac{I_{o} T \pi}{2 n \cdot 2 \pi \sqrt{L_{s} C_{r}}}=\frac{1}{2} V_{i n}+\frac{I_{m}}{4 C_{r}}\left(T-T_{1}\right)+\frac{I_{o} T}{4 n C_{r}}-\frac{I_{o} T \pi L_{s}}{4 n C_{r} \pi L_{s}} \\
=\frac{1}{2} V_{i n}+\frac{I_{m}}{4 C_{r}}\left(T-T_{1}\right) \\
=\frac{1}{2} V_{i n}+\frac{n V_{o} T_{1}}{4 L_{m}} \times \frac{T-T_{1}}{4 C_{r}} \\
V_{o}=\frac{V_{i n}}{2 n}+\frac{V_{o} T_{1}}{4 L_{m}} \times \frac{T-T_{1}}{4 C_{r}}
\end{gathered}
$$




$$
\begin{aligned}
& =\frac{V_{i n}}{2 n}+\frac{V_{0} T_{1}}{4 L_{m}} \times \frac{T-T_{1}}{4} \times \frac{4 \pi^{2} L_{s}}{T_{1}^{2}} \\
= & \frac{V_{i n}}{2 n}+\frac{V_{o}}{4 L_{m}} \times\left(T-T_{1}\right) \times \frac{\pi^{2} \cdot L_{s}}{T_{1}} \\
= & \frac{V_{i n}}{2 n}+\frac{L_{s} V_{o}}{4 L_{m} T_{1}} \pi^{2}\left(T-T_{1}\right) \\
= & \frac{V_{i n}}{2 n}+\frac{\pi^{2} L_{s} V_{o}}{4 L_{m}}\left(\frac{f_{r 1}}{f}-1\right) \\
L_{m} & =\frac{\pi^{2} L_{s}}{4 f_{\min }} \times \frac{f_{r 1}-f_{\min }}{1-\left(V_{i n \min } / 2 n V_{o \max }\right)}
\end{aligned}
$$

Where, $f$ is the cycle frequency at time $T$. $V_{\text {inmin }}$ is the minimum input voltage and $V_{\text {omax }}$ is the maximum output voltage.

\section{MATHCAD Simulation}

The main focus of designing resonant network parameters is to adjust $\mathrm{Lm}, \mathrm{Cr}$ and $\mathrm{Ls}$ according to ZVS and ZCS conditions. We can analyze the relationship of transfer function between the input voltage and output voltage with respect to ideal normalized frequency $(f n)$, quality factor $(Q)$ and $h(L s / L m)$. The above formulas are verified by MATHCAD-based simulation. We explore amplitude-frequency characteristic of the transmission voltage gain $\mathrm{m}(f n, h, Q)$. $f n\left(f_{s} / f r_{1}\right)$ is the ratio of switching frequency and first resonant frequency, and $h$ is the ratio of resonant inductor $L_{s}$ and excitation inductance $L m$.

$$
\begin{gathered}
Q=\left(\pi^{2} / 8 n^{2} R_{o}\right) \times \sqrt{L s / C r} \\
m\left(f_{n}, h, Q\right)=\frac{1}{\sqrt{\left(1+h-\frac{h}{f_{n}^{2}}\right)+Q^{2}\left(f_{n}-\frac{1}{f_{n}}\right)^{2}}}
\end{gathered}
$$

\section{Simulation of LLC Waveform}

The key problem of designing a half-bridge LLC resonant converter lies in the selection and optimization of the resonant network parameters. Reasonable parameters are the prerequisite to achieve soft-switching performance [6] and make LLC resonant circuit works in the best zone.

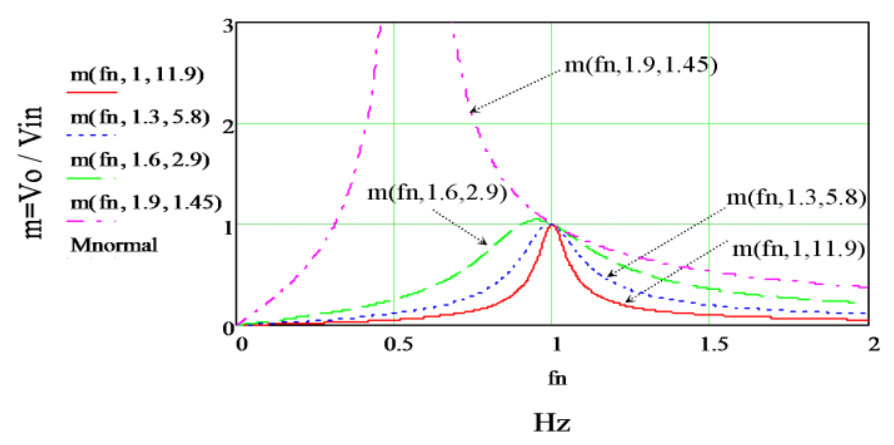

Fig.4 Simulation waveform of LLC working zone

As shown in Fig. 4, LLC resonant circuit working zone can be divided into three different modes according to different switching frequency $f s$. Circuit works in capacitive zone when the switching frequency is less than $\operatorname{fr}_{1}\left(f_{n}<1\right)$. Circuit works in inductive zone when the switching frequency is 
greater than $f r_{l}(\mathrm{fn}>1)$. Therefore half-bridge resonant circuit has a relatively high load regulation. The phase angle of resonant current $L s$ lags behind the phase angle of drive square-wave voltage $V_{G S 1}$ and $V_{G S 2}$. This is a necessary condition for ZVS appearing in the inductive zone.

\section{The Effect of Varying $Q$}

As shown in Fig. 5, gain waveform changes with varying $Q$ when $\mathrm{h}=0.5$. It shows that gain $m$ becomes larger with the decrease of $Q$, and switching frequency range $f s$ is smaller. Voltage gain $m$ will become smaller as the $Q$ becomes larger, and switching frequency range $f s$ becomes larger and wider. Working performance of the resonant components is poor. So designing reasonable $Q$ under full load condition is especially important.

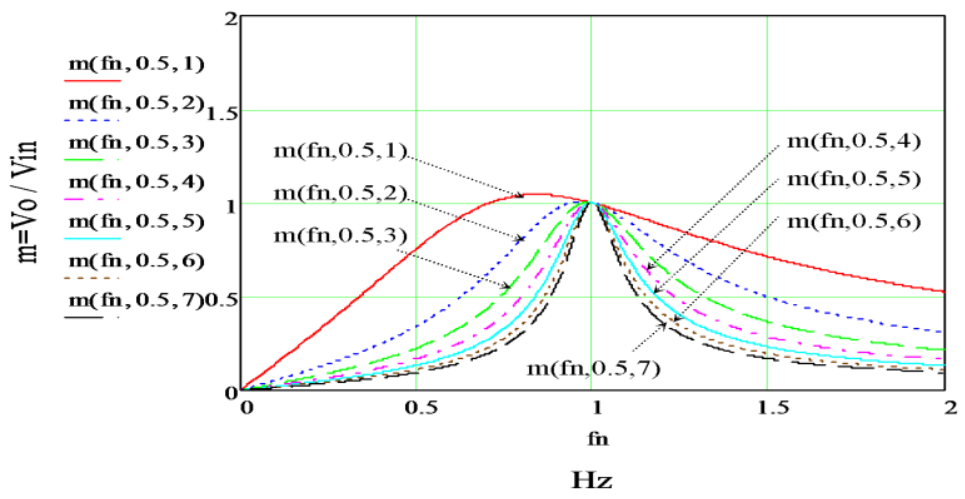

Fig. 5 Simulation waveform of voltage gain with varying $Q$

\section{The Effect of Varying $h$}

As shown in Fig. 6, gain waveform changes with varying $h$ when $\mathrm{n}=8$ and $\mathrm{Q}=5$. Maximum voltage gain increases when $h$ increases. But $h$ is smaller when $L m$ becomes smaller and $L s$ is certain. The greater the loss of the resonant inductance Ls, the lower the efficiency is [8]. Designing $h$ should be taken maximum gain and normalized frequency range $f n$ into account.

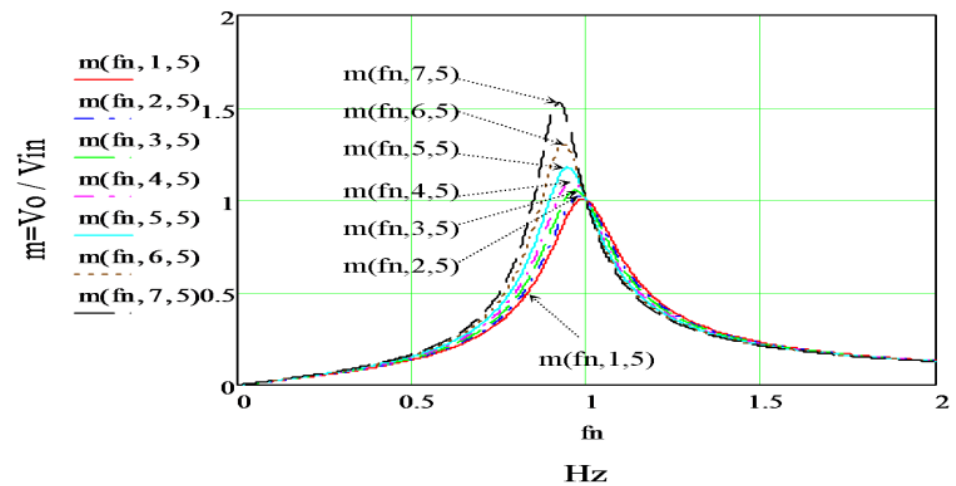

Fig. 6 Gain waveform with varying $h$

\section{Analysis of SABER Simulation}

Through the above analysis of the principle and simulation waveform of resonant network ideal working zone, this paper selects an output of ' $310 \mathrm{~W} / 24.8 \mathrm{~V}$ ' LLC resonant converter as a simulation prototype. MATHCAD soft design is used to optimize the parameters which are simulated by SABER software. The following parameters are used as follow:

Minimum input voltage: $V_{\text {inmin }}=250 \mathrm{~V}$

Maximum input voltage: $\mathrm{V}_{\text {inmax }}=430 \mathrm{~V}$ 
Normal input voltage: $\mathrm{V}_{\text {innor }}=400 \mathrm{~V}$

Minimum switching frequency: $\mathrm{f}_{\mathrm{smin}}=100 \mathrm{KHz}$

Maximum switching frequency: $\mathrm{f}_{\mathrm{smax}}=156.3 \mathrm{KHz}$

First resonance frequency: $\mathrm{f}_{\mathrm{r} 1}=140 \mathrm{KHz}$

Resonant capacitor: $\mathrm{C}_{\mathrm{r}}=12.92 \mathrm{nF}$

Resonant inductor: $\mathrm{L}_{\mathrm{s}}=100.1 \mathrm{uH}$

Magnetizing inductance: $\mathrm{Lm}=263.3 \mathrm{uH}$

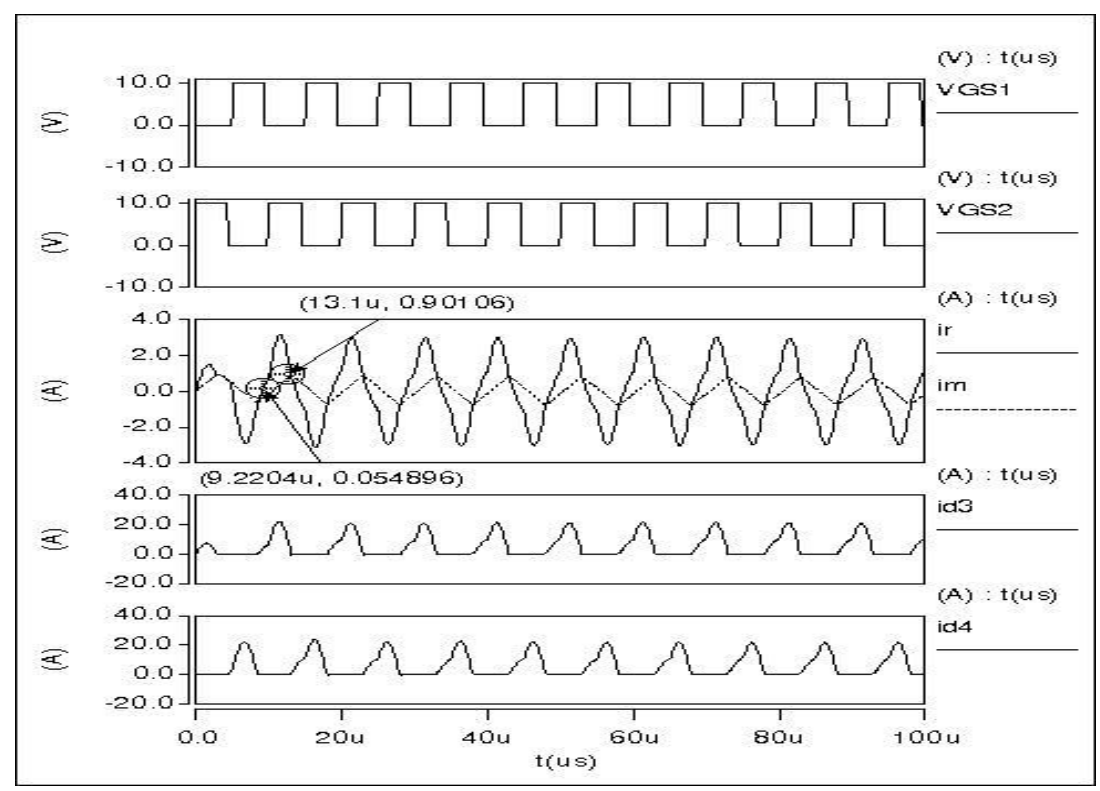

Fig. 7 SABER simulation waveform of resonant network

Figure 7 shows simulation waveform of resonant network elements. One can observe that the excitation inductance current $i_{m}$ linearly rises and maximizes to $\mathrm{Im}_{\mathrm{m}}(0.9 \mathrm{~V})$ at time $13.1 \mathrm{us}$ which equals to harmonic current $i$. So it verifies the working principle as shown in Fig. 3. On the interval (0,100us), harmonic current $i_{r}$ is quasi-sine wave and it reduces the power consumption [9]. The two square waves are respectively voltage waveform of $V_{G S 1}$ and $V_{G S 2}$, and they increase alternately. Current waveform of $i_{d 3}$ and $i_{d 4}$ alternately increase. Simulation results achieve soft-switching performance of ZVS.

\section{Simulation and Measurement Results}

LED drive power supply should meet electromagnetic interference (EMI) and PFC standards with the characteristics of high energy efficiency and reliability. It is necessary for us to use high PFC circuit to decrease EMI $[10,11]$. This paper designs a high efficient half-bridge drive power supply (200w/310v) which is based on 'PFC-LLC' topology. First using SABER soft to simulate the designed schematic diagrams of PFC circuit, and then we verify tested waveform of the whole designed circuit.

\section{Simulation and Measured Waveform of PFC Circuit}

By comparing the simulation waveform (Fig. 8) with the measured waveform (Fig. 9), we observe that the input voltage and current in the same phase angle. The current is zero when the voltage is zero-crossing, and in this case that the input harmonic is reduced greatly. So the efficiency of the designed power supply is improved. The power efficiency reaches $91.5 \%$ which is $3.5 \%$ higher than the LED drive power supply which is involved in literature [12], but power factor is $95.6 \%$ which is $1.4 \%$ smaller than it. Considering from the whole power performance, the designed power supply meets optimization criteria. 


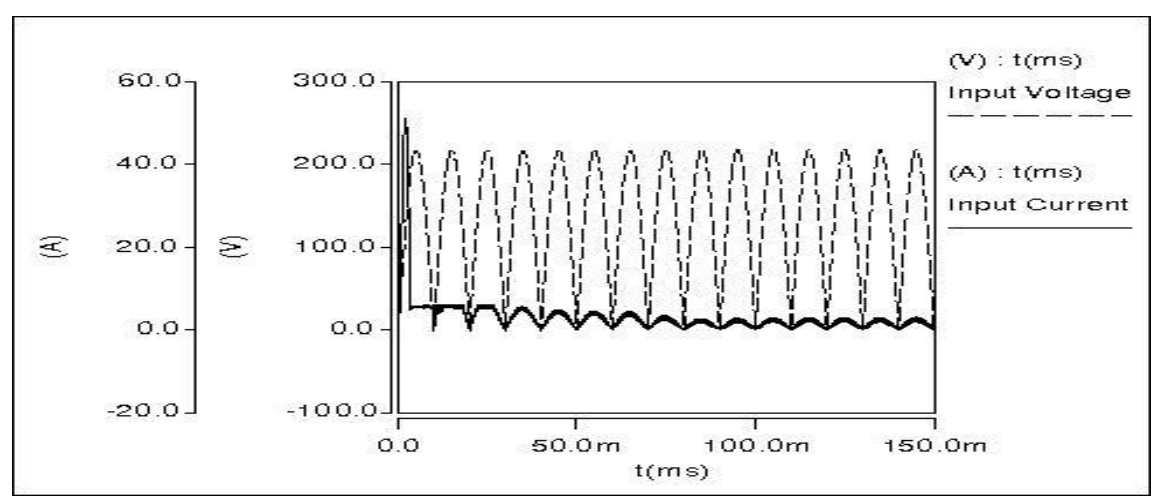

Fig.8 Simulation waveform of input voltage and current

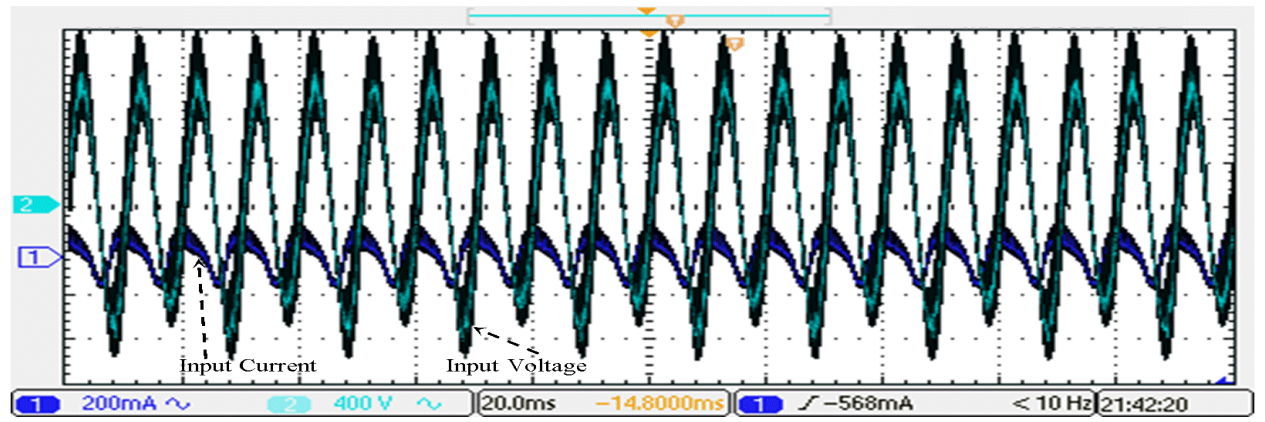

Fig.9 Measured waveform of input voltage and current

\section{Measured Current of Secondary Diodes}

As shown in Fig. 10 that R1 channel is current $i_{d 3}$ and 1 channel is current $i_{d 4}$. The two current waveforms alternately increase, it illustrates that the current of rectifier diodes achieves the ZCS performance.

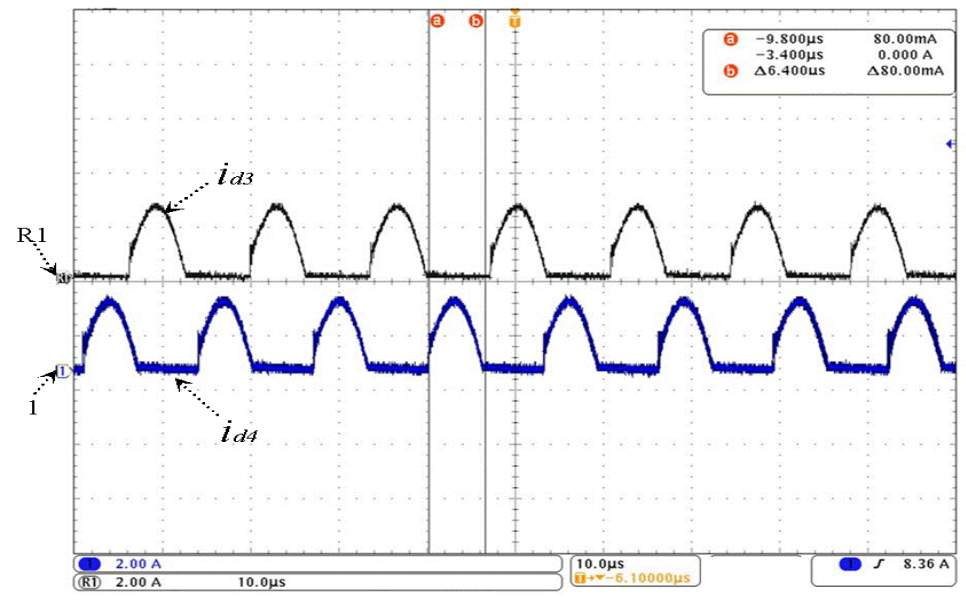

Fig.10 Current waveform of $i_{d 3}$ and $i_{d 4}$

\section{Analysis of Conducted Emission Test}

Fig. 11 shows the tested result of conducted emission from $9 \mathrm{kHz}$ to $30 \mathrm{MHz}$ by EN55015 standard. It indicates the tested emission with the designed PFC circuit nonlinearity under the limit value by average $15 \mathrm{~dB}$. So the designed driver power supply in this paper has low EMI interference. 


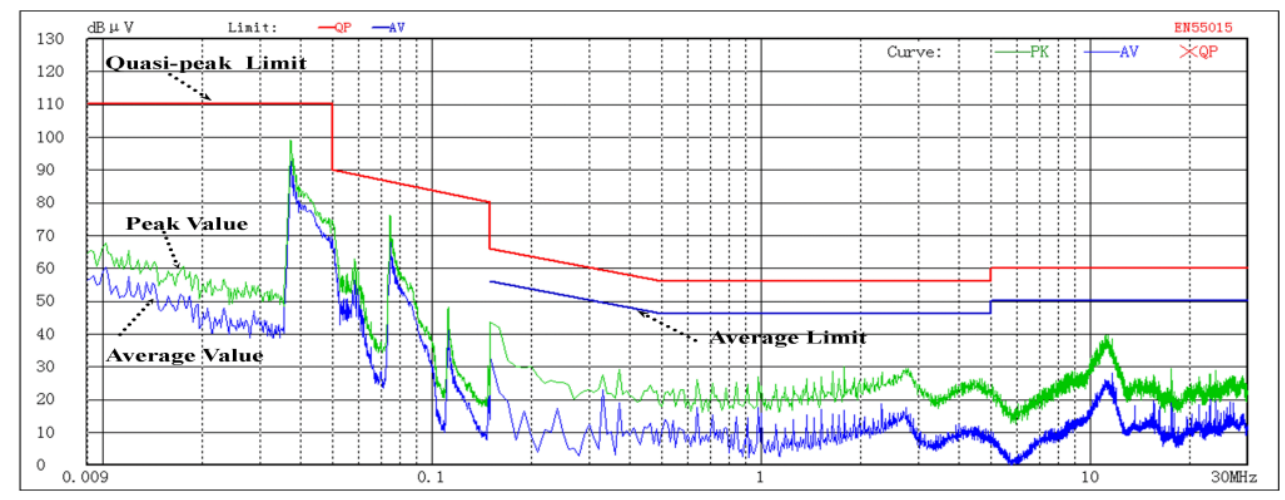

Fig. 11 Waveform of conducted emission test

\section{Conclusions}

Design and analysis of a half-bridge LED drive resonant power supply of PFC-LLC topology with ST6562 and L6599 as the core of the controllers is presented in this paper. The designed and optimized parameters of harmonic components are verified by extensive simulation as well as testbed results. The conduction losses of power switch decrease to a minimum range with the characteristics of high efficiency and low EMI interference. Results obtained have shown that one can choose optimized parameters to achieve improved system performance. Our design method achieves the desired goals in terms of high power density and smooth electromagnetic interference.

\section{Acknowledgments}

This work was supported in part by 2013 National Natural Science Foundation of China under Grant (No. 61379027)

\section{References}

1. Musavi, F., Craciun, M., Gautam, D.S., Eberle, W. and Dunford, W.G.: 'An LLC resonant DCDC converter for wide output voltage range battery charging applications', IEEE Transactions on Power Electron.,2013, 28, 12, pp. 5437-5445, (2013)

2. Wang, H.Y, Dusmez, S. and Khaligh, A.: 'Design considerations for a level-2 on-board PEV charger based on interleaved boost PFC and LLC resonant converters', Transportation Electrification Conference and Expo (ITEC)., Detroit, MI, USA, pp. 1-8, (2013)

3. Beiranvand R., Rashidian, B., Zolghadri, M. R. and Alavi, S. M. H.: 'Using LLC resonant converter for designing wide-range voltage source,' IEEE Transactions on Ind. Electron., 2011, 58, 5, pp. 1746-1756, (2010)

4. Beiranvand, R. Rashidian, B. Zolghadri, M. R. and Alavi, S. M. H.: 'A design procedure for optimizing the LLC resonant converter as a wide output range voltage source,' IEEE Transactions on Power Electron., 2012, 27, 8, pp. 3749-3763, (2012)

5. Musavi, F., Craciun, M., Edington, M., Eberle, W. and Dunford, W. G.: 'Practical design considerations for a LLC multi-resonant DC-DC converter in battery charging applications,' Applied Power Electronics Conference and Exposition(APEC)., Orlando, FL, USA, February 2012, pp. 2596-2602, (2012)

6. Lai, C.M., Lee, R.C., Wang, T.W. and Shyu, K.K.: 'Design and implementation of a singlestage LLC resonant converter with high power factor,' Int. Symp. Ind. Electron., Vigo, Spain, pp. 455-460, (2007) 
7. Bhat, A.K.S. and Venkatraman, R.: 'A soft-switched full-bridge single-stage AC-to-DC converter with low-line-current harmonic distortion,' IEEE Transactions on Industrial Electronics., 2005, 52, (4), pp. 1109-1116, (2005)

8. Yang, B., Chen, R. and Lee, F.C.: 'Integrated magnetic for LLC resonant converter,' Appl. Power Electron. Conf. Expo., Dallas, TX, USA, March 2002, pp. 346-351, (2002)

9. Fu, D.B., Kong, P.J., Wang, S., Lee, F.C. and Xu, M.: 'Analysis and suppression of conducted EMI emissions for front-end LLC resonant DC/DC converters,' Power Electron. Spec. Conf(PESC)., June 2008, pp. 1144-1150, (2008)

10. Moo C.S., Lee, K.H., Cheng, H.L. and Chen, W.M.: 'A single-stage high-power-factor electronic ballast with ZVS buck-boost conversion,' IEEE Transactions on Ind. Electron., 2008, 56, 4, pp. 1136-1146, (2008)

11. Musavi, F., Eberle, W. and Dunford, W.G.: 'A high-performance single-phase bridgeless interleaved PFC converter for plug-in hybrid electric vehicle battery chargers,' IEEE Transactions on Ind. Appl.,2011, 47, 4, pp. 1833-1843, (2011)

12. Ou, S.Y. and Hsiao H.P.: 'Analysis and design of a novel single-stage switching power supply with half-bridge topology,' IEEE Transactions on Power Electronics., 2011, 26, 11, pp. 3230-3241, (2011) 